\title{
BMJ Open Examination of the community-specific prevalence of and factors associated with substance use and misuse among Rural and Urban adolescents: a cross- sectional analysis in Bosnia and Herzegovina
}

\author{
Natasa Zenic, ${ }^{1}$ Ljerka Ostojic,,${ }^{1,2,3}$ Nedim Sisic, ${ }^{1}$ Haris Pojskic, ${ }^{4}$ Mia Peric, ${ }^{1}$ \\ Ognjen Uljevic, ${ }^{1}$ Damir Sekulic ${ }^{1,5}$
}

To cite: Zenic N, Ostojic L, Sisic N, et al. Examination of the community-specific prevalence of and factors associated with substance use and misuse among Rural and Urban adolescents: a cross-sectional analysis in Bosnia and Herzegovina. BMJ Open 2015;5:e009446. doi:10.1136/bmjopen-2015009446

- Prepublication history for this paper is available online. To view these files please visit the journal online (http://dx.doi.org/10.1136/ bmjopen-2015-009446)

Received 21 July 2015 Revised 13 October 2015 Accepted 16 October 2015

CrossMark

For numbered affiliations see end of article.

Correspondence to Professor Damir Sekulic; dado@kifst.hr

\section{ABSTRACT}

Objective: The community of residence (ie, urban vs rural) is one of the known factors of influence on substance use and misuse (SUM). The aim of this study was to explore the community-specific prevalence of SUM and the associations that exist between scholastic, familial, sports and sociodemographic factors with SUM in adolescents from Bosnia and Herzegovina.

Methods: In this cross-sectional study, which was completed between November and December 2014, the participants were 957 adolescents (aged 17 to 18 years) from Bosnia and Herzegovina (485; 50.6\% females). The independent variables were sociodemographic, academic, sport and familial factors. The dependent variables consisted of questions on cigarette smoking and alcohol consumption. We have calculated differences between groups of participants (gender, community), while the logistic regressions were applied to define associations between the independent and dependent variables.

Results: In the urban community, cigarette smoking is more prevalent in girls $(\mathrm{OR}=2.05 ; 95 \% \mathrm{Cl} 1.27$ to 3.35), while harmful drinking is more prevalent in boys (OR=2.07; $95 \% \mathrm{Cl} 1.59$ to 2.73 ). When data are weighted by gender and community, harmful drinking is more prevalent in urban boys $(\mathrm{OR}=1.97 ; 95 \% \mathrm{Cl}$ 1.31 to 2.95), cigarette smoking is more frequent in rural boys $(\mathrm{OR}=1.61 ; 95 \% \mathrm{Cl} 1.04$ to 2.39$)$, and urban girls misuse substances to a greater extent than rural girls $(\mathrm{OR}=1.70 ; 95 \% \mathrm{Cl} 1.16$ to $2.51,0 \mathrm{R}=2.85 ; 95 \% \mathrm{Cl}$ 1.88 to $4.31,0 \mathrm{R}=2.78 ; 95 \% \mathrm{Cl} 1.67$ to 4.61 for cigarette smoking, harmful drinking and simultaneous smoking-drinking, respectively). Academic failure is strongly associated with a higher likelihood of SUM. The associations between parental factors and SUM are more evident in urban youth. Sports factors are specifically correlated with SUM for urban girls.

Conclusions: Living in an urban environment should be considered as a higher risk factor for SUM in girls. Parental variables are more strongly associated with SUM among urban youth, most probably because of

\section{Strengths and limitations of this study}

- Owing to the cross-sectional nature of the study, we were not able to discuss the causality but only the association between studied variables.

- Participants may lean towards socially desirable answers, but knowing that cigarette smoking and alcohol consumption are relatively common and socially accepted behaviours in the country decreased the possibility that participants did not respond honestly.

- Academic achievement was self-reported and therefore may not be absolutely reliable and an accurate presentation of scholastic variables, but the testing was done at the beginning of the school year, so we believe that it was correctly reported.

- This is one of the first studies to examine the community-specific context of SUM in adolescents from the wider territory of former Yugoslavia, with the main intention of determining those factors worth studying in forthcoming prospective investigations.

- This is one of the first studies to examine the problem of SUM and related factors among European Muslim youth and results show the specific prevalence and characteristic associations between the studied factors.

the higher parental involvement in children' personal lives in urban communities (ie, college plans, for example). Specific indicators should be monitored in the prevention of SUM.

\section{INTRODUCTION}

Cigarette smoking and alcohol drinking are the most common types of substance use and misuse (SUM) among adolescents. ${ }^{1}$ Daily 
smoking rates in European countries range mostly from $10 \%$ to $20 \%$. More specifically, among the countries with the lowest daily smoking prevalence in adolescence are Sweden (5\% and $14 \%)$, the UK $(10 \%$ and $17 \%)$ and Switzerland $(13 \%$ and $13.0 \%$ for boys and girls, respectively). The highest daily smoking rates among adolescents are reported for Hungary (17\% and 19\%), Belgium (17\% and 19\%), Bosnia and Herzegovina (25\% and $15 \%$ ), and Austria (20\% and $25 \%$ for boys and girls, respectively). ${ }^{1-4}$ Additionally, with approximately $30 \%$ of adolescents who self-reported harmful alcohol drinking, Bosnia and Herzegovina is clearly one of the European countries with the highest prevalence of SUM in Europe. ${ }^{145}$

These disturbing figures on adolescent SUM are mostly explained by tradition and heritage (ie, growing tobacco has been a significant part of the economy in Bosnia and Herzegovina for more than three centuries) and social acceptance of alcohol consumption and cigarette smoking (ie, smoking is allowed in public places and there is no strict regulation against drinking alcohol in public), as well as by post-war trauma, known political problems and a lack of a general and effective prevention policy. ${ }^{35}$

The place of residence (ie, community) is one factor that could directly or indirectly influence SUM. ${ }^{6}{ }^{7}$ The investigations that examined the difference in SUM prevalence between adolescents living in urban and rural areas mostly found differences between individual communities. ${ }^{8-11}$ However, the results were not consistent. Some studies found a lower likelihood of smoking, ${ }^{8}$ alcohol consumption, ${ }^{9}$ or smoking and alcohol consumption ${ }^{12}$ among adolescents from rural communities. Other studies, however, found a higher prevalence of SUM in rural youth. ${ }^{10} 11$

As a result of the high prevalence of SUM on the territory that was formerly Yugoslavia (including Bosnia and Herzegovina), public health authorities and academicians put special emphasis on evidencing factors potentially related to SUM in adolescence. ${ }^{3} 5$ However, studies conducted so far are inconsistent with regard to associations that may exist between sports, sociodemographic, familial and scholastic factors and among adolescents. ${ }^{13}$ One of the probable reasons for the variable findings of the studies conducted thus far is the fact that none of the studies stratified participants with regard to urban/rural communities. In particular, despite the growing efforts to explain the problem of SUM, no attention has been given to examining the differences between rural and urban adolescent SUM and the potential risk and protective factors in these locations. Also, practically all studies done so far have examined ethnic Croats from Croatia and Bosnia and Herzegovina, ${ }^{1} 5{ }^{13}$ while there is an evident lack of studies that specifically investigated other ethnicities and religions.

The aim of this cross-sectional study was to explore the community-specific (ie, urban/rural) associations between scholastic, familial, sports and sociodemographic factors and alcohol consumption and cigarette smoking in adolescents from Bosnia and Herzegovina. Additionally, we have examined the gender-specific and community-specific prevalence of SUM and associated factors in the study participants. In this study, we have specifically investigated the problems among ethnic Bosniak adolescents (Muslims by religion).

\section{METHODS}

\section{Participants}

In this cross-sectional study, we examined 957 adolescents (aged 17 to 18 years) from Tuzla Canton and Zenic-Doboj Canton (485 girls). and Zenica-DobojCanton (485 girls). At the time of testing, all of the participants were in their final year of high school. For the purpose of the investigation, we randomly selected one-third of the high schools in the Cantons, with half from each group. The testing took place during one morning school shift (school is organised into two shifts), and we attempted to test approximately $50 \%$ of the seniors from the selected schools. Originally, the testing was intended to include more participants, but for the purpose of this study we selected only those children who declared themselves as traditionally (inherited) Muslim (religion will be discussed later in the paper). Ultimately, the sample studied in this paper represented $6 \%$ of the high school students in the observed cantons. The sample is described in table 1 .

\section{Variables}

For the purpose of this study, we used an extensive, previously validated, self-administered questionnaire. ${ }^{1}$ The independent variables observed were sociodemographic, academic achievement, sports and familial factors. The dependent variables consisted of questions on SUM. We asked children about their cigarette smoking and alcohol consumption habits.

Sociodemographic factors included age, gender, place of residence, financial situation (below average, average, above average), religion/ethnicity (responses included Bosniak-Muslim; Bosniak-Other; Croatian-Catholic; Croatian-Other; Serbian-Orthodox; Serbian-Other; Other) and strength of religious beliefs as measured by the Santa Clara Strength of Religious Faith (SCSRF). ${ }^{14} 15$ All participants who reported a place of

\begin{tabular}{|c|c|c|c|c|}
\hline & \multicolumn{2}{|c|}{$\begin{array}{l}\text { Zenica Doboj } \\
\text { Canton }\end{array}$} & \multicolumn{2}{|c|}{ Tuzla Canton } \\
\hline & Boys & Girls & Boys & Girls \\
\hline Urban & 44 & 94 & 90 & 110 \\
\hline Rural & 113 & 105 & 225 & 176 \\
\hline Total & 157 & 199 & 315 & 286 \\
\hline
\end{tabular}


residence of less than 10000 inhabitants were grouped as a 'rural-dwelling' while those who reported a place of residence of more than 10000 inhabitants were classified as an 'urban-dwelling'. The population was defined according to the Bosnian and Herzegovinian Agency for Statistics. ${ }^{16}$

Academic achievement was determined using four questions on participants' academic achievement over the past academic year: (1) grade point average (a fivepoint scale ranging from excellent to poor); (2) behavioural grade (a five-point scale ranging from excellent to poor); (3) unexcused school absences (number of nonexcused absences measured in teaching hours; a fivepoint scale ranging from 'less than $5 \mathrm{~h}$ ' to ' $20 \mathrm{~h}$ or more'); and (4) overall school absence (a four-point scale ranging from 'almost never' to 'often').

Sports factors included questions on the amount of time they have spent in sports (in years) and their most significant competitive achievements in sports.

Apart from maternal and paternal educational level, and financial status of the family, the familial factors consisted of the following questions: (1) "How often do you have a conflict with your parents?" (2) "How often are your parents absent from home, including for their work obligations?" (3) "How often do your parents ask you questions about your friends, scholastic achievements, problems, and other personal issues?" and (4) "How would you rate how much your parents care about you and your personal life?).

Cigarette smoking was evaluated on a six-point scale ('Never smoked,' 'Quit,' 'Smoking from time to time, but not daily,' 'Smoking fewer than 10 cigarettes per day,' 'Smoking 10 to 20 cigarettes per day,' and 'Smoking more than a pack of cigarettes per day'). The children were then grouped as 'non-smokers' (Never smoked and Quit) and 'smokers' (all remaining answers). Alcohol consumption was measured using the Alcohol Use Disorders Identification Test (AUDIT) questionnaire, comprising 10 items with the scores for each item ranging from 0 to 4 . The questionnaire defines a hypothetical range of $0-40$. For the purpose of this study, the results were later divided into 'harmful drinking' (scores of 11 and above) and 'non-harmful drinking' (scores below 11). Those participants who indicated smoking and harmful alcohol drinking were categorised as simultaneous SUM (multiple SUM).

\section{Testing and ethics}

The study was completed between November and December 2014. Testing was strictly anonymous, meaning that no personal data were collected. Prior to testing, the design and aim of the study were explained to all participants and at least one parent for each participant. Parental consent was obtained. Testing occurred in a classroom with groups of at least 11 participants. Participants were informed that they could refuse to participate and that they could leave some questions and/or the entire questionnaire unanswered and that returning the questionnaire would be considered their consent for participation in the study. When the testing was completed, each participant placed the questionnaire in a closed box. The next day, the boxes were opened by an investigator who had not tested the participants. The study was approved by the corresponding author's Institutional Ethical Board and Cantonal Ministries of Education.

\section{Statistics}

We have calculated frequencies (ie, counts) and percentages. Differences between the studied communities were tested by means of the Mann-Whitney test and independent samples $\mathrm{t}$ test. To determine whether the observed communities and genders had different outcomes on a specific SUM measure, the OR with 95\% CI was calculated. To determine independent variables associated with SUM, we calculated forward conditional stepwise logistic regressions. The criteria were binomial SUM variables (smoking vs non-smoking; harmfuldrinking vs non-harmful-drinking; multiple SUM vs nonmultiple SUM). Analyses were stratified by community. Statistica V.12 (Statsfot, Tulsa, Oklahoma, USA) was used for all analyses and statistical significance was set at $\mathrm{p}<0.05(95 \%)$.

\section{RESULTS}

\section{Gender and community differences for SUM}

$29 \%$ boys and $32 \%$ girls smoked cigarettes, with no significant difference between genders. For urban-dwelling adolescents, smoking is more prevalent in girls while smoking is more prevalent in urban girls than in rural girls. Rural boys smoked more frequently than did urban boys (figure 1).

Boys are more likely to be involved in harmful drinking than girls, with $42 \%$ boys and $27 \%$ girls who declared harmful drinking habits. Rural boys are evidently more prone to harmful drinking than rural girls while the likelihood of harmful drinking is significantly greater among urban boys than urban girls. Harmful drinking is higher among urban boys than among rural boys, urban girls and rural girls (figure 2).

Multiple SUM is prevalent in $17 \%$ boys and $15 \%$ girls, with a significantly higher likelihood of multiple SUM among boys but only for rural-dwelling adolescents. Urban girls are at higher risk of multiple SUM (23\%) than rural-dwelling-girls (10\%) (figure 3).

When boys were compared between communities for independent variables, urban boys reported more school absences (MW=2.50; $\mathrm{p}=0.01$ ) (table 1), longer involvement in sports (MW=3.65; $\mathrm{p}=0.01)$ (table 2), higher levels of conflict with parents (MW=3.07; $\mathrm{p}=0.01$ ) and higher maternal (MW=4.92; $\mathrm{p}=0.01$ ) and paternal (MW=5.17; $\mathrm{p}=0.01$ ) levels of education than rural boys.

Rural girls participate in sports for shorter periods (MW=5.67; $\mathrm{p}=0.01$ ) and achieve lower competitive results (MW=6.55; $\mathrm{p}=0.01$ ) than urban girls. Maternal 


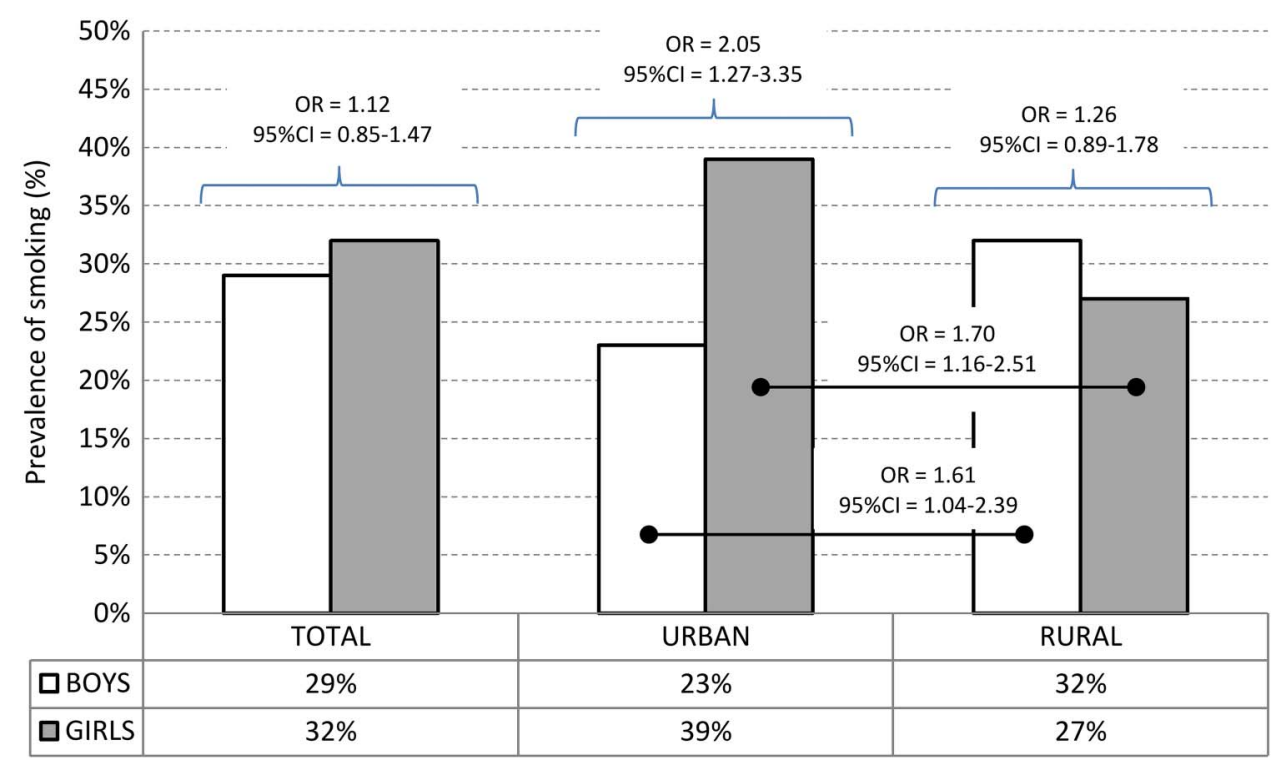

Figure 1 Prevalence of cigarette smoking with OR between and within genders. Percentage of reported frequency for boys and girls with $n=472$ and $n=485$, respectively, being $100 \%$.

education ( $\mathrm{MW}=8.66 ; \mathrm{p}=0.01$ ) and paternal education $(\mathrm{MW}=5.48 ; \mathrm{p}=0.01)$ are higher in urban girls. Urban-dwelling girls reported more frequent parental absences from home (MW=3.80; $\mathrm{p}=0.01)$ and higher levels of conflict with parents (MW=2.54 $\mathrm{p}=0.01$ ).

The level of religiousness is higher among rural-dwelling adolescents for both boys $(26.95 \pm 8.45$ and $30.42 \pm 7.63$; for urban and rural boys, respectively; $\mathrm{t}$ test $=4.32, \mathrm{p}<0.01)$ and girls $(26.01 \pm 7.36$ and $32.02 \pm 6.42$ for urban and rural girls, respectively; $\mathrm{t}$ test $=9.52$, $\mathrm{p}<0.01)$.

A higher likelihood of cigarette smoking is evidenced in rural boys with lower behavioural grades $(\mathrm{OR}=2.66$; $95 \%$ CI 1.83 to 3.87 ) and who reported a poorer financial situation $(\mathrm{OR}=0.29 ; 95 \%$ CI 0.10 to 0.85$)$. The logistic regression equation successfully classified $70 \%$ of participants (table 2 ).

Lower behavioural grades (OR=1.94; $95 \%$ CI 1.38 to 2.73) together with lower levels of religiousness $(\mathrm{OR}=0.96 ; 95 \%$ CI 0.93 to 0.99$)$ contribute significantly to the prevalence of harmful alcohol drinking among rural boys, with $69 \%$ of rural boys successfully classified (table 2).

Harmful alcohol drinking is more frequent among urban boys who achieved a lower grade-point average in the preceding school year (OR=1.67; 95\% CI 1.02 to 2.73), who were absent from school more frequently $(\mathrm{OR}=1.63 ; 95 \%$ CI 1.09 to 2.43$)$, and whose parents

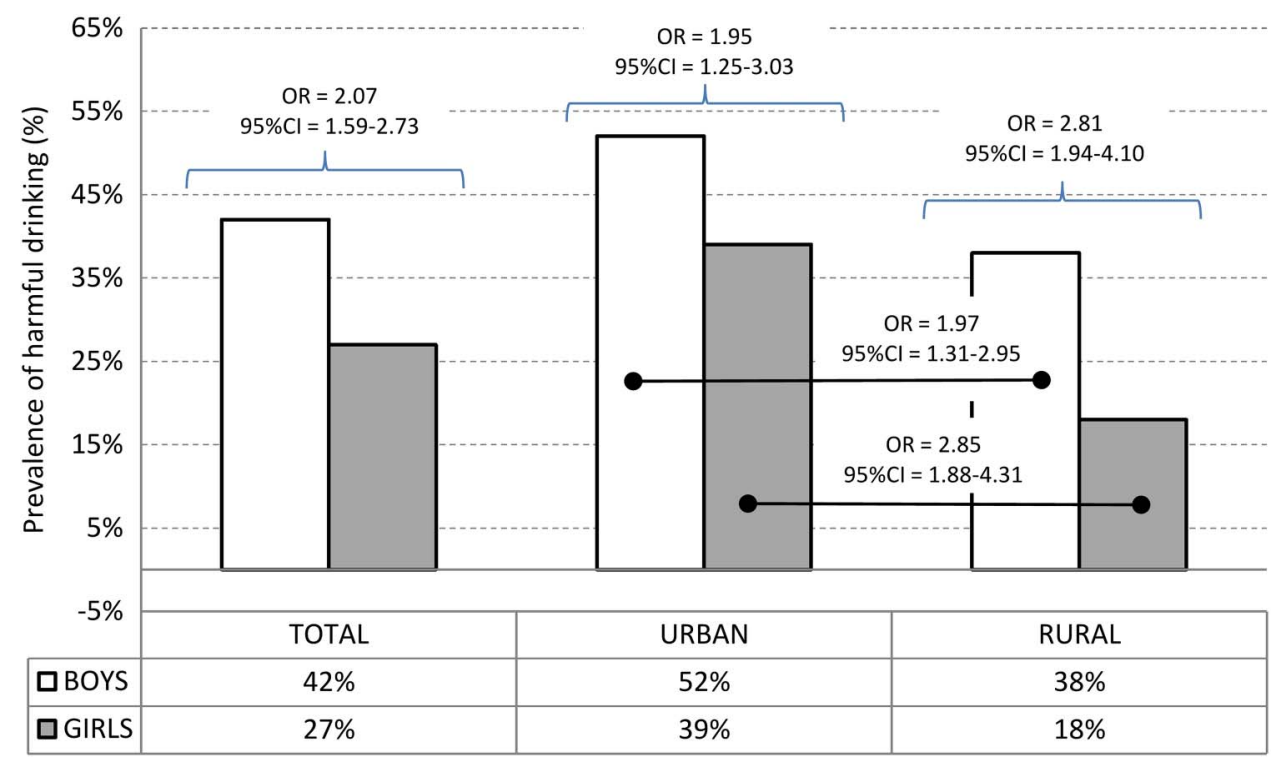

Figure 2 Prevalence of harmful alcohol drinking with OR between and within genders. Percentage of reported frequency for boys and girls with $n=472$ and $n=485$, respectively, being $100 \%$. 


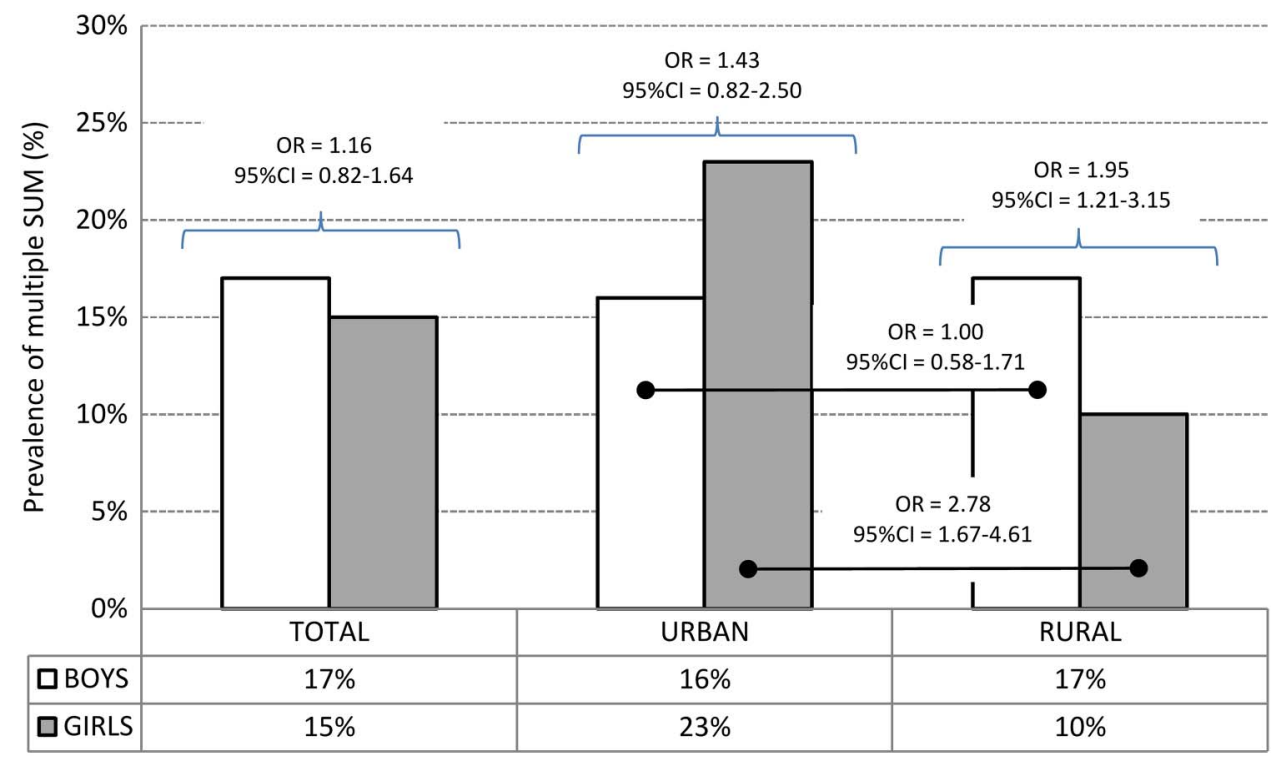

Figure 3 Prevalence of multiple substance use and misuse (simultaneous harmful drinking and cigarette smoking) with OR between and within genders. Percentage of reported frequency for boys and girls with $n=472$ and $n=485$, respectively, being $100 \%$.

were frequently absent from home, including because of job duties ( $\mathrm{OR}=1.79 ; 95 \%$ CI 1.15 to 2.79$)$. In total, $67.2 \%$ of the participants were successfully classified (table 2).

Multiple SUM is higher in rural boys with more unexcused school absences ( $\mathrm{OR}=1.74 ; 95 \%$ CI 1.14 to 2.65$)$, lower behavioural grades $(\mathrm{OR}=2.09 ; 95 \%$ CI 1.38 to $3.19)$, poorer finances $(\mathrm{OR}=0.22 ; 95 \%$ CI 0.06 to 0.830$)$ and lower levels of religion $(\mathrm{OR}=0.94 ; 95 \%$ CI 0.90 to $0.97)$. At the final step, the model successfully classified $85 \%$ of the participants (table 2).

A higher prevalence of multiple SUM among the urban boys was related to more frequent parental absences from home (OR=1.91; 95\% CI 1.05 to 3.50). The model successfully classified $84 \%$ of the participants (table 2).

The logistic regression calculated for cigarette smoking successfully classified $75.5 \%$ of rural girls. A higher prevalence of smoking is evidenced in those girls with low educational achievement ( $\mathrm{OR}=1.41 ; 95 \%$ CI 1.303 to 2.014), lower behavioural grades $(\mathrm{OR}=6.65$; 95\% CI 2.02 to 21.85) and greater amounts of conflict with parents (OR=1.52; 95\% CI 1.10 to 2.10) (table 3).

Smoking in urban girls is associated with a lower grade point average ( $\mathrm{OR}=2.53 ; 95 \%$ CI 1.71 to 3.76$)$, more frequent parental absences $(\mathrm{OR}=2.70 ; 95 \%$ CI 1.77 to 4.15$)$, frequent parental questioning $(\mathrm{OR}=2.76$; $95 \%$ CI 1.67 to 4.58$)$, a lower level of religion $(\mathrm{OR}=0.85$; $95 \%$ CI 0.80 to 0.90 ) and longer involvement in sports $(\mathrm{OR}=2.54 ; 95 \%$ CI 1.11 to 6.14$)$, while being less successful $(\mathrm{OR}=0.52 ; 95 \%$ CI 0.06 to 0.86$)$. In total, $87 \%$ of urban girls were successfully classified by the logistic regression calculation (table 3 ).

When calculated for the harmful alcohol drinking criterion, logistic regression was successful for $81 \%$ of the rural girls. A higher prevalence of harmful drinking is evidenced in girls with a higher number of unexcused absences $(\mathrm{OR}=2.06$; $95 \%$ CI 1.31 to 1.3 .25$)$ (table 3$)$.

A higher prevalence of harmful alcohol drinking among urban girls is associated with lower scholastic achievement by means of grade point average $(\mathrm{OR}=2.31$; $95 \%$ CI 1.41 to 3.82), longer involvement in sports $(\mathrm{OR}=4.09 ; 95 \%$ CI 1.79 to 9.23$)$, and high competitive achievement (OR=3.11;95\% CI 1.55 to 8.13), better finances (OR=9.47; 95\% CI 2.02 to 44.12) and higher levels of conflict with parents $(\mathrm{OR}=6.65 ; 95 \%$ CI 3.06 to 14.47 ), with $88 \%$ of girls successfully classified (table 3 ).

Logistic regression revealed a higher prevalence of multiple SUM in rural girls who had more unexcused school absences (OR=4.14; 95\% CI 1.23 to 8.14), with $82 \%$ of the girls being successfully classified (table 3 ).

Multiple SUM in urban girls is more prevalent among girls with lower grade point averages $(\mathrm{OR}=3.50 ; 95 \%$ CI 2.23 to 5.15$)$ and better finances ( $\mathrm{OR}=11.72 ; 95 \%$ CI 4.18 to 32.83 ) and whose parents are more frequently absent from home (OR=3.77; 95\% CI 2.01 to 7.07). The model successfully classified $85 \%$ of urban girls (table 3).

\section{DISCUSSION}

With regard to the main study aim, there are several significant findings. In general, data showed higher SUM in urban adolescents, and this is particularly evident among girls. Second, academic achievement is the factor most significantly associated with SUM in both communities while the association between parental factors and SUM is more evidenced in urban youth. Finally, sport factors were associated with SUM only in urban girls. 
Table 2 Stepwise forward conditional logistic regression results for the criteria cigarette smoking, harmful drinking and multiple substance use and misuse (Multiple SUM) among rural and urban dwelling boys

\begin{tabular}{|c|c|c|c|c|c|c|}
\hline & \multicolumn{2}{|c|}{ Cigarette smoking } & \multicolumn{2}{|l|}{ Harmful drinking } & \multicolumn{2}{|l|}{ Multiple SUM } \\
\hline & $\begin{array}{l}\text { Urban boys } \\
\text { OR }(95 \% \mathrm{CI})\end{array}$ & $\begin{array}{l}\text { Rural boys } \\
\text { OR (95\% Cl) }\end{array}$ & $\begin{array}{l}\text { Urban boys } \\
\text { OR }(95 \% \mathrm{CI})\end{array}$ & $\begin{array}{l}\text { Rural boys } \\
\text { OR (95\% Cl) }\end{array}$ & $\begin{array}{l}\text { Urban boys } \\
\text { OR }(95 \% \mathrm{Cl})\end{array}$ & $\begin{array}{l}\text { Rural boys } \\
\text { OR (95\% Cl) }\end{array}$ \\
\hline Grade point average & & & 1.67 (1.02 to 2.73 ) & & & \\
\hline School absence & & & 1.63 (1.09 to 2.43 ) & & & \\
\hline Unexcused absence & & & & & & 1.74 (1.14 to 2.65$)$ \\
\hline Behavioural grade & & 2.66 (1.83 to 3.87 ) & & 1.94 (1.38 to 2.73 ) & & 2.09 (1.38 to 3.19$)$ \\
\hline Financial status & & $0.29(0.10$ to 0.85$)$ & & & & $0.22(0.06$ to 0.83$)$ \\
\hline Parental absence & & & 1.79 (1.15 to 2.79$)$ & & 1.91 (1.05 to 3.50$)$ & \\
\hline SCSRF & & & & 0.96 (0.93 to 0.99$)$ & & 0.94 (0.90 to 0.97$)$ \\
\hline
\end{tabular}

Table 3 Stepwise forward conditional logistic regression results for the criteria cigarette smoking, harmful drinking and multiple substance use and misuse (multiple SUM) among rural and urban dwelling girls

\begin{tabular}{|c|c|c|c|c|c|c|}
\hline & \multicolumn{2}{|l|}{ Cigarette smoking } & \multicolumn{2}{|l|}{ Harmful drinking } & \multicolumn{2}{|l|}{ Multiple SUM } \\
\hline & $\begin{array}{l}\text { Urban girls } \\
\text { OR }(95 \% \mathrm{Cl})\end{array}$ & $\begin{array}{l}\text { Rural girls } \\
\text { OR (95\% Cl) }\end{array}$ & $\begin{array}{l}\text { Urban girls } \\
\text { OR }(95 \% \mathrm{Cl})\end{array}$ & $\begin{array}{l}\text { Rural girls } \\
\text { OR }(95 \% \mathrm{Cl})\end{array}$ & $\begin{array}{l}\text { Urban girls } \\
\text { OR (95\% Cl) }\end{array}$ & $\begin{array}{l}\text { Rural girls } \\
\text { OR }(95 \% \mathrm{Cl})\end{array}$ \\
\hline Grade point average & 2.53 (1.71 to 3.76$)$ & $1.41(1.30$ to 2.01$)$ & 2.31 (1.41 to 3.82 ) & & & 3.50 (2.23 to 5.15$)$ \\
\hline Unexcused absence & & & & 2.06 (1.31 to 3.25$)$ & 4.14 (1.23 to 8.14$)$ & \\
\hline Behavioural grade & & 6.65 (2.02 to 21.85 ) & & & & \\
\hline Financial status & & & 9.47 (2.02 to 44.12$)$ & & & 11.72 (4.18 to 32.83$)$ \\
\hline Parental absence & 2.70 (1.77 to 4.15$)$ & & & & & 3.77 (2.01 to 7.07 ) \\
\hline Conflict with parents & & $1.52(1.10$ to 2.10$)$ & 6.65 (3.06 to 14.47 ) & & & \\
\hline Parental questioning & 2.76 (1.67 to 4.58$)$ & & & & & \\
\hline Participation in sports & 2.54 (1.11 to 6.14$)$ & & 4.09 (1.79 to 9.23$)$ & & & \\
\hline Sport achievement & 0.52 (0.06 to 0.86$)$ & & 3.11 (1.55 to 8.13$)$ & & & \\
\hline SCSRF & 0.85 (0.80 to 0.90$)$ & & & & & \\
\hline
\end{tabular}


Prior to discussing those findings, we will provide a discussion of the community-specific prevalence in SUM.

The overall prevalence of SUM in studied adolescents is consistent with previous studies on the subject, which found consumption of cigarettes and alcohol to be alarming. ${ }^{3} 5$ As a result, findings on the differences between urban and rural communities with regard to SUM are particularly important. The higher prevalence of SUM in urban-dwelling than in rural-dwelling girls is almost certainly related to the overall sociocultural influence of the urban community on youth behaviour. In general, Bosnia and Herzegovina is a traditional country where gender roles are (relatively) defined. ${ }^{5}{ }^{17} \mathrm{~A}$ number of studies have shown that adherence to traditionalism and the female gender role has been linked to lower SUM. ${ }^{18}{ }^{19}$ However, in urban centres, traditionalism is not so apparent. ${ }^{1}$ Consequently, it is clear that cigarette smoking is more prevalent in urban than in rural girls. With regard to alcohol, another issue deserves attention. In particular, girls' alcohol drinking is socially accepted only in night clubs and bars. Since such places are mainly located within urban centres, it logically increases alcohol consumption in urban girls. Boys from rural communities misuse cigarettes to a greater extent than their urban-dwelling peers. Cigarette smoking is likely to be generally more accepted and viewed as a cultural norm in rural than urban areas, to the point where rural parents may not perceive boys' smoking as a disturbing issue. ${ }^{20}$ However, it is also possible that a lack of other free-time activities (ie, sports, extracurricular activities, etc.) together with social acceptance of smoking has resulted in higher cigarette smoking among rural boys. One of the unique findings of this study is that urban girls smoke more frequently than urban boys. In explaining this finding, we must highlight that contrary to alcohol drinking, cigarette smoking in Bosnia and Herzegovina is a socially acceptable behaviour for girls. This is particularly true in urban centres, where girls frequently present their 'nontraditionalism' and emancipation by smoking. Together with the previously discussed difference between urban-dwelling and rural-dwelling girls in SUM (ie, urban girls misuse substances to a greater extent than rural girls), living in an urban environment should be considered a factor of 'increased risk' for SUM in girls.

Parental/familial factors have generally been found to be a protective factor against SUM in adolescence. ${ }^{21} 22$ In a recent investigation, the authors reported different associations between parental factors and SUM for urban and rural Latin American (Latino) youth. ${ }^{20}$ With regard to gender, our findings on the stronger influence of parental variables on SUM habits in girls are consistent with that study. On the other hand, we have found there to be stronger parental influence on SUM in urban boys, which is in contrast with the findings reported for Latino youth, where the authors found a stronger association between parental factors and SUM for rural children. ${ }^{20}$ In explaining this inconsistency, we must highlight that our respected colleagues observed 14-18-year-olds while we have studied 17-18-year-olds. Parental monitoring generally decreases with age, and urban youth are more likely to continue their education at the college level. ${ }^{5}$ Therefore, it is reasonable to expect that parents of urban boys are more involved in their personal lives than is the case for their rural peers. The level of religiousness was found to be specifically associated with SUM (ie, urban girls for cigarette smoking and rural boys for harmful drinking). In both cases, a lower likelihood of misusing substances is evidenced in more religious subjects. The level of religiousness (ie, commitment to religious beliefs, traditions and norms) has already been studied with regard to its potential protective effects against substance misuse in adolescents. However, the findings have not been consistent. The results from a US study ${ }^{23}$ show that religiousness reduces the odds of tobacco use among adolescents. Conversely, a Mexican study found that adolescents with lower church attendance and those who place a lower importance on religion are less likely to consume cigarettes. ${ }^{24}$ Although there is some recent evidence that Muslim adolescents have significantly lower rates of substance misuse than Christians (all Middle Eastern youth), ${ }^{25}$ this study is one of the first that specifically reported on the association between Islamic religiousness and substance misuse in adolescents. Academic achievement is one of the factors consistently found to be associated with SUM in adolescents. ${ }^{3}{ }^{5}$ Therefore, our findings on the negative association between most of the educational variables and smoking and drinking support previous findings. While this study was cross-sectional, and we were not able to define the true cause-effect relationships between academic achievement and SUM (ie, it is not clear whether adolescents started to abuse substances and then failed educationally or vice versa), some pathways are intuitively obvious. In particular, it is almost certain that SUM (harmful drinking and multiple SUM; see Results section) actually led to more unexcused absences. However, this is one of the rare studies that defined the association between academic achievement and SUM simultaneously for urban and rural communities, and the results are consistent with the other results recently presented. ${ }^{20}$

Studies frequently examined the potential association between sport (ie, physical exercising) and cigarette smoking. ${ }^{3} 1326$ This investigation extends previous knowledge of associations between sport factors and SUM by emphasising the specific multivariate association of poor competitive achievement and long participation with a higher likelihood of smoking in urban girls. It is possible that those girls who smoke cannot meet the physical demands of sports competition, which consequently results in poor performance (regardless of the long participation in sports). Additionally, it is possible that those girls who did not have high achievement in sports despite being in a sport for a prolonged period 
started to smoke. For a more detailed analysis, a prospective study on the problem is needed. The negative association between competitive achievement and alcohol consumption in girls did not surprise us. In particular, studies have frequently reported high alcohol consumption among athletes and sport fans. ${ }^{27-30}$ In girls, this is mostly explained by (1) frequent out of home situations, (2) post-sport gatherings, and (3) lower levels of traditionalism in those girls involved in sports. ${ }^{1} 3132$ We are convinced that all these factors to some extent led to the association between competitive results and alcohol consumption in urban girls. Those girls who achieve higher competitive results are (1) more frequently absent from home (because of sports competitions). The competitive successes are regularly followed by (2) gatherings where alcohol is consumed for 'relaxation'. Finally (3), in traditional countries (such as Bosnia and Herzegovina), girls' participation in sports and alcohol drinking are both more common in more 'liberal' families. ${ }^{5}$ The fact that an association between sport factors and alcohol consumption is found solely in urban girls is a logical reflection of the clear differences between urban and rural girls in regard to sports (rural girls participate in sports less frequently; see Results section).

The following conclusions can be drawn. In general, urban youth consume substances more often than their rural peers. However, smoking prevalence, which is higher in rural-dwelling than in urban-dwelling boys, led us to the conclusion that rural areas are moving away from being the protective communities they were once thought to be and are seeing an increase in deviant behaviours once viewed as exclusively urban occurrences. Some specific factors of influence on SUM should be noted. First, academic achievement seems to be systematically related to SUM in both genders and both communities that were studied. Therefore, special attention should be placed on those children who perform poorly in school. Also, sports factors are characteristically related to SUM solely among urban girls, while the highest SUM is found in those girls who participate in sports for a prolonged period while being less successful. The true cause-effect relationship for all observed factors should be more precisely investigated through prospective studies. In so doing, a culturally specific and community-specific approach is needed.

\section{Author affiliations \\ ${ }^{1}$ Faculty of Kinesiology, University of Split, Split, Croatia \\ ${ }^{2}$ University of Mostar, Mostar, Bosnia and Herzegovina \\ ${ }^{3}$ Academy of Medical Sciences of Bosnia and Herzegovina, Sarajevo, Bosnia and Herzegovina \\ ${ }^{4}$ Department for Health Sciences, Mid Sweden University, Östersund, Sweden \\ ${ }^{5}$ University Department of Health Care Studies, Split, Croatia}

Acknowledgements The authors thank the Cantonal Ministries of Education, Science, Culture and Sport who supported and approved the investigation. They are also particularly grateful to all children who voluntarily participated in the study.
Contributors NZ designed the study, performed statistical analysis and discussed the data. LO collected the data, drafted the manuscript and discussed the results; NS and HP collected the data and overviewed the previous research; MP overviewed the previous researches; OU participated in the study design and drafted the manuscript; DS did preliminary statistical procedures and discussed the data. All authors have read and approved the final version.

Funding This research received no specific grant from any funding agency in the public, commercial or not-for-profit sectors.

Competing interests None declared.

Provenance and peer review Not commissioned; externally peer reviewed.

Ethics approval The Ethical Boards of University of Split, Faculty of Kinesiology, Split, Croatia and University of Mostar, School of Medicine, Mostar, Bosnia and Herzegovina approved the Investigation. Additionally, the study was approved by the Cantonal Ministries of Education.

Data sharing statement No additional data are available.

Open Access This is an Open Access article distributed in accordance with the Creative Commons Attribution Non Commercial (CC BY-NC 4.0) license, which permits others to distribute, remix, adapt, build upon this work noncommercially, and license their derivative works on different terms, provided the original work is properly cited and the use is non-commercial. See: http:// creativecommons.org/licenses/by-nc/4.0/

\section{REFERENCES}

1. Sekulic D, Ostojic M, Ostojic Z, et al. Substance abuse prevalence and its relation to scholastic achievement and sport factors: an analysis among adolescents of the Herzegovina-Neretva Canton in Bosnia and Herzegovina. BMC Public Health 2012;12:274.

2. Hublet A, De Bacquer D, Valimaa R, et al. Smoking trends among adolescents from 1990 to 2002 in ten European countries and Canada. BMC Public Health 2006;6:280.

3. Sekulic D, Ostojic M, Vasilj M, et al. Gender-specific predictors of cigarette smoking in adolescents: an analysis of sport participation, parental factors and religiosity as protective/risk factors. J Subst Use 2014;19:89-94.

4. ESPAD report. http://www.espad.org/Uploads/ESPAD_reports/2011/ FULL\%20REPORT\%20-\%20Supplement\%20to\%20The\%202011\% 20ESPAD\%20Report\%20-\%20WEB.pdf

5. Cerkez I, Culjak Z, Zenic N, et al. Harmful Alcohol Drinking Among Adolescents: The Influence of Sport Participation, Religiosity, and Parental Factors. J Child Adoles Subst 2015;24:94-101.

6. Singh A, Sahoo N. Urban-rural differentials in the factors associated with exposure to second-hand smoke in India. BMJ Open 2013;3: e003542.

7. Pawłowska B, Zygo M, Potembska E, et al. Psychoactive substances use experience and addiction or risk of addiction among by Polish adolescents living in rural and urban areas. Ann Agric Environl Med 2014;21:776-82.

8. Peer N, Bradshaw D, Laubscher R, et al. Urban-rural and gender differences in tobacco and alcohol use, diet and physical activity among young black South Africans between 1998 and 2003. Global Health Act 2013;6:1-10.

9. McDermott MJ, Drescher CF, Smitherman TA, et al. Prevalence and sociodemographic correlates of lifetime substance use among a rura and diverse sample of adolescents. Subst Abus 2013;34:371-80.

10. Donath C, Grässel E, Baier D, et al. Predictors of binge drinking in adolescents: ultimate and distal factors-a representative study. BMC Public Health 2012;12:263.

11. Sygit K, Kolltaj W, Wojtyta A, et al. Engagement in risky behaviours by 15-19-year-olds from Polish urban and rural areas. Ann Agr Env Med 2011;18:404-9.

12. Gutiérrez JP, Atienzo EE. Socioeconomic status, urbanicity and risk behaviors in Mexican youth: an analysis of three cross-sectional surveys. BMC Public Health 2011;11:900.

13. Modric T, Zenic N, Sekulic D. Substance use and misuse among 17- to 18-year-old Croatian adolescents: correlation with scholastic variables and sport factors. Subst Use Misuse 2011;46:1328-34.

14. Zenic N, Stipic M, Sekulic D. Religiousness as a factor of hesitation against doping behavior in college-age athletes. J Relig Health 2013;52:386-96. 
15. Cavar M, Sekulic D, Culjak Z. Complex interaction of religiousness with other factors in relation to substance use and misuse among female athletes. J Relig Health 2012;51:381-9.

16. Agency for Statistics of Bosnia and Hercegovina. http://www.bhas.ba/

17. Vasilj I, Pilav A, Maslov B, et al Cardiovascular risk factors research in Bosnia and Herzegovina. Coll Antropol 2009;33 (Suppl 2):185-8.

18. Kulis S, Marsiglia FF, Hurdle D. Gender identity, ethnicity, acculturation, and drug use: exploring differences among adolescents in the southwest. J Community Psychol 2003;31:167-88.

19. Wahl AM, Eitle TM. Gender, acculturation and alcohol use among Latina/o adolescents: a multi-ethnic comparison. J Immigr Minor Health 2010;12:153-65.

20. Zhen-Duan J, Taylor MJ. The Use of an Ecodevelopmental Approach to Examining Substance Use Among Rural and Urban Latino/a Youth: Peer, Parental, and School Influences. J Ethn Subst Abuse 2014;13:104-25.

21. Branstetter SA, Furman W. Buffering effect of parental monitoring knowledge and parent-adolescent relationships on consequences of adolescent substance use. J Child Fam Stud 2013;22:192-8.

22. Mason WA, Haggerty KP, Fleming AP, et al. Family intervention to prevent depression and substance use among adolescents of depressed parents. J Child Fam Stud 2012;21:891-905.

23. Kiesner J, Poulin F, Dishion TJ. Adolescent substance use with friends: moderating and mediating effects of parental monitoring and peer activity contexts. Merrill Palmer Q 2010;56:529-56.

24. Bachman JG, O'Malley PM, Johnston LD, et al. Racial/ethnic differences in the relationship between parental education and substance use among U.S. 8th-, 10th-, and 12th-grade students: findings from the Monitoring the Future project. J Stud Alcohol Drugs 2011;72:279-85.

25. Badr LK, Taha A, Dee V. Substance abuse In Middle Eastern adolescents living in two different countries: spiritual, cultural, family and personal factors. J Relig Health 2014;53:1060-74.

26. Hedman L, Andersson M, Stridsman C, et al. Evaluation of a tobacco prevention programme among teenagers in Sweden. BMJ Open 2015;5:e007673.

27. Sekulic D, Bjelanovic L, Pehar M, et al. Substance use and misuse and potential doping behaviour in rugby union players. Res Sports Med 2014;22:226-39.

28. Martens MP, Dams-O'Connor K, Duffy-Paiement C, et al. Perceived alcohol use among friends and alcohol consumption among college athletes. Psychol Addict Behav. 2006;20:178-84.

29. Barry AE, Howell SM, Riplinger A, et al. Alcohol use among college athletes: do intercollegiate, club, or intramural student athletes drink differently? Subst Use Misuse 2015;50:302-7.

30. Kingsland M, Wiggers J, Wolfenden L. Interventions in sports settings to reduce alcohol consumption and alcohol-related harm: a systematic review protocol. BMJ Open 2012;2:e000645.

31. Zenic N, Peric M, Zubcevic NG, et al. Comparative analysis of substance use in ballet, dance sport, and synchronized swimming: results of a longitudinal study. Med Probl Perform Art 2010;25:75-81.

32. Kondric M, Sekulic D, Petroczi A, et al. Is there a danger for myopia in anti-doping education? Comparative analysis of substance use and misuse in Olympic racket sports calls for a broader approach. Subst Abuse Treat Prev Policy 2011;6:27. 